\title{
Construction of a new plant expression vector and the development of maize germplasm expressing the Aspergillus ficuum phytase gene PhyA2
}

\author{
Peng Jiao • Wen-Ya Yuan · Han-Dan Zhao · Jing Qu • Pi-Wu Wang • \\ Shu-Yan Guan · Yi-Yong Ma
}

Received: 5 March 2020/Accepted: 22 October 2020/Published online: 9 November 2020

(C) The Author(s) 2020

\begin{abstract}
Phytases, which belong to a special category of orthophosphoric monoester phosphohydrolases, degrade inositol hexaphosphate to produce lower-grade inositol phosphate derivatives and inorganic phosphate. Thus, phytases may improve phosphorus utilization, eliminate the anti-nutrient properties of phytic acid, and mitigate environmental pollution due to phosphorus contamination. In this study, we constructed a new rootspecific expression vector by inserting the Aspergillus ficuum phytase gene PhyA2 into pCAMBIA3301ZmGLU1P-Nos. The subsequent molecular analysis confirmed that six $\mathrm{T}_{4}$ generation transgenic plants carried and expressed PhyA2. A quantitative real-time PCR analysis indicated PhyA2 was highly expressed in the transgenic roots. Additionally, the phytase activity was 10.9-fold higher in the transgenic roots (peak activity of $5.432 \mathrm{U} / \mathrm{g}$ ) than in the control roots. Moreover, compared with the control rhizosphere, the organic phosphorus content in the rhizosphere of the transgenic plants decreased significantly (by up to $5.21 \mathrm{mg} / \mathrm{kg}$ ). An agronomic trait analysis indicated that $P h y A 2$ expression can increase maize seed weight by up to $25.8 \mathrm{~g}$.
\end{abstract}

P. Jiao - W.-Y. Yuan · H.-D. Zhao ·

J. Qu · P.-W. Wang · S.-Y. Guan $(\bowtie) \cdot$ Y.-Y. Ma ( $ه)$

Key Laboratory of Crop Molecular Breeding in Jilin

Province, Jilin Agricultural University,

Changchun 130000, China

e-mail: m18404319202_1@126.com

Y.-Y. Ma

e-mail: 1596162461@qq.com
Therefore, the integration of PhyA2 into the maize genome can enhance the ability of maize plants to use the phosphorus compounds in soil, while also improving the plant growth status and increasing the seed yield.

Keywords Aspergillus ficuum · Phytase gene · Expression vector - Maize
Abbreviations
6-BA 6-Benzylaminopurine
Bar Herbicide
Carb Carbenicillin
Cef Cefradine
IBA $1 \mathrm{~h}$-Indole-3-butanoic acid
Kan Kanamycin
KT Kinetin
NAA 1-Naphthaleneacetic acid

\section{Introduction}

As one of the three most important crops, maize is widely used, including as food, feed, and industrial raw materials (Wu et al. 2014). Early maize producers used traditional crop breeding techniques to develop and cultivate many excellent maize varieties. Recently, genetic engineering and transgenic techniques have been applied to transfer genes associated with specific functions into maize inbred lines to enhance crop 
quality and specific plant traits. Advances in molecular breeding research have provided researchers with new options for the genetic improvement of maize.

Phosphorus is one of the nutrients essential for maize growth and development. Soil organic phosphorus is an important source of phosphorus nutrients for maize (Sareh et al. 2018). Organic phosphorus represents approximately $20-80 \%$ of the total phosphorus content in soil, with more than $50 \%$ of the organic phosphorus existing as phytate phosphorus, which is difficult for plants to absorb and use (Enqing et al. 2018). Phytate phosphorus is also an important form of phosphorus in maize plants, especially in seeds, wherein it accounts for about $70 \%$ of the total phosphorus content. However, the digestive tract of monogastric animals lacks enzymes to hydrolyze phytate phosphorus, resulting in its excretion into the environment in feces. This not only decreases the phosphorus utilization by animals, it also increases environmental pollution due to organic phosphorus (Yan 2012). Additionally, phytate phosphorus can chelate other metal ions to form compounds that are relatively insoluble. Therefore, phytate phosphorus is also known as an anti-nutrient factor. Phytases are a class of enzymes that can catalyze the hydrolysis of phytate phosphorus and release inorganic phosphate and inositol that can be passively absorbed and used by plants (Valeeva et al. 2018).

In this study, the PhyA2 gene, which encodes a phytase, was cloned from Aspergillus ficuum and used to construct a new plant expression vector containing a root-specific promoter. By applying genetic engineering technology, the recombinant plasmid was inserted into a maize inbred line. The root-specific expression of PhyA2 increased the phytase content and activity to improve the degradation of the organic phosphorus in soil, enabling the transgenic maize plants to absorb more phosphorus and efficiently degrade phytic acid salt. The results of this study may be useful for producing new maize germplasm that can efficiently use phosphorus to increase the crop yield.

\section{Materials and methods}

Experimental strains, plasmid vector, and plant receptor material

Aspergillus ficuum was purchased from the Institute of Microbiology, Chinese Academy of Sciences.
Escherichia coli DH5 $\alpha$ and Agrobacterium tumefaciens EHA105 cells, the modified plant expression vector pCAMBIA3301-ZmGLU1P-Nos, and the germinal callus cells of maize inbred line GSH9901 were provided by the Key Laboratory of Crop Molecular Breeding in Jilin Province, China.

Media

Murashige and Skoog (MS) liquid medium ( $\mathrm{pH}$ 5.8) was used as the A. tumefaciens infection solution. Differentiation medium 1 (MS1) comprised MS liquid medium supplemented with $2 \mathrm{~mL}$ 6-BA, 1 mL NAA, $30 \mathrm{~g} / \mathrm{L}$ sucrose, and $7.5 \mathrm{~g}$ agar (pH 5.8). Differentiation medium 2 (MS2) comprised MS1 supplemented with $50 \mathrm{mg} / \mathrm{L}$ Kan, $400 \mathrm{mg} / \mathrm{L} \mathrm{Carb}$, and $600 \mathrm{mg} / \mathrm{L} \mathrm{Bar}$ (pH 5.8). Screening rooting medium (MS3) comprised MS liquid medium supplemented with $1 \mathrm{~mL}$ NAA, 50 mg/L Kan, 400 mg/L Carb, 600 mg/L Bar, $30 \mathrm{~g} / \mathrm{L}$ sucrose, and $7.5 \mathrm{~g}$ agar $(\mathrm{pH} 5.8)$.

Preparation of the maize embryo and induction of the embryogenic callus

Young maize ears (10-13 days old) were selected. The outer bract was removed, leaving a layer of leaves, after which the maize ears were washed with $75 \%$ ethanol for $15 \mathrm{~min}$. The leaves were peeled off and the palpus was removed before the maize ears were disinfected with $0.5 \% \mathrm{NaClO}$ solution for $10 \mathrm{~min}$ and then rinsed with sterile water 3-4 times. In an ultraclean workbench, a scalpel was used to cut the maize kernels. After removing the seed coat and endosperm, the young embryo was transferred to N6 medium for a 15-day incubation at $25^{\circ} \mathrm{C}$ in darkness.

\section{Cloning of PhyA2 from Aspergillus ficuum}

The A. ficuum PhyA sequence (AF537344.1) available in the GenBank database was used to design genespecific primers (S and AS) with the Primer Premier

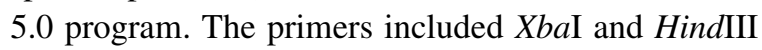
restriction enzyme sites. Details regarding the primer sequences are provided in Table 1.

Total RNA was extracted from A. ficuum using a commercial RNAiso plus extraction kit (Bao Bioengineering (Dalian) Co., Ltd., Economic and Technological Development Zone, Dalian City, Liaoning Province, China) and then reverse transcribed to 
cDNA. The cDNA was used as the template for a PCR amplification of the target gene (PhyA2) with primers $\mathrm{S}$ and AS. The PCR conditions are listed in Table 2. The PCR product was analyzed by agarose gel electrophoresis. After purifying the amplified PhyA2 fragment from the gel, it was inserted into the pMD18$\mathrm{T}$ vector. The resulting $\mathrm{pMD} 18-\mathrm{T}-\mathrm{Phy} \mathrm{A} 2$ recombinant plasmid was sequenced to confirm the accuracy of the PhyA2 sequence.

\section{Construction of a new plant expression vector}

The pMD18-T-PhyA2 plasmid and the modified plant expression vector pCAMBIA3301-ZmGLU1P-Nos were digested with $X b a \mathrm{I}$ and HindIII and then analyzed by agarose gel electrophoresis. The PhyA2 gene fragment and the linearized plant expression vector sequence were recovered and ligated with $\mathrm{T}_{4}$ DNA ligase. The resulting new plant expression vector was analyzed by a PCR amplification and a restriction enzyme digestion to confirm it was constructed correctly. The process involved in constructing the new plant expression vector is presented in Fig. 1.

Transformation of maize with the plant expression vector

The PhyA2 gene was inserted into maize inbred line GSH9901 embryonic calli via A. tumefaciens-mediated transformation. The optimized infection and transformation conditions were as follows: 25-30 min for the A. tumefaciens infection of calli; the bacterial culture was used after reaching an optical density at $600 \mathrm{~nm}\left(\mathrm{OD}_{600}\right)$ of $0.6-0.7$; and 2-3 days for the co-culture required for the A. tumefaciensmediated transformation. After screening for herbicide (Glufosinate) resistance, calli were differentiated. When the herbicide-resistant calli on the differentiation medium 1 grew to 3-5 cm with 3-4 leaves, the seedlings were transferred to the rooting medium. Approximately 15-25 days later, 4-6 robust primary roots and many fibrous roots were detected. The seedlings were incubated at $23-26{ }^{\circ} \mathrm{C}$ for $2-3$ days, after which they were transplanted to pots containing sterilized soil.

Insertion of the plant expression vector into maize

\section{Agrobacterium tumefaciens culturing}

Agar-solidified YEB medium supplemented with $50 \mathrm{mg} / \mathrm{L}$ Kan was inoculated with A. tumefaciens cells containing the recombinant plant expression vector carrying PhyA2. The culture was incubated at $28{ }^{\circ} \mathrm{C}$ for 2 days. An individual colony was added to a test tube containing $5 \mathrm{~mL} \mathrm{YEP/Kan} \mathrm{medium.} \mathrm{The}$ culture was oscillated (180 rpm) overnight at $28{ }^{\circ} \mathrm{C}$. A 3 - $\mathrm{mL}$ aliquot of the overnight culture was added to $50 \mathrm{~mL}$ YEP/Kan medium, after which the culture was incubated at $28{ }^{\circ} \mathrm{C}$, with shaking at $220 \mathrm{rpm}$. When the $\mathrm{OD}_{600}$ of the bacterial culture reached approximately 0.7 , the culture was centrifuged at $5000 \mathrm{rcf}$ for $20 \mathrm{~min}$ at room temperature to collect the bacteria. The bacterial cells were resuspended in the same volume of MS liquid medium.

\section{Callus transformation and co-culturing}

The callus was added to $50 \mathrm{~mL}$ infection solution in a sterile culture bottle, which was then shaken for $6 \mathrm{~min}$. The infected callus was removed from the bottle, placed on sterile filter paper to absorb the excess infection solution, and then transferred to the coculture medium for a 2-day incubation in darkness.

\section{Screening and culturing}

After the co-culture step, the embryogenic callus exhibiting healthy growth (e.g., soft and pale yellow) was transferred to the screening medium for an incubation at $28{ }^{\circ} \mathrm{C}$ under light. The medium was refreshed every 15 days.
Table 1 Primer sequences

The underlined part is the restriction enzyme digestion site

\begin{tabular}{ll}
\hline Name & Primer sequences \\
\hline PhyA2-S & TTTAAGCTTACTGGCAGTCCCCGCCTCGAGAAATC \\
PhyA2-AS & TTTTCTAGACTAAGCAAAACACTCCGCCCAAT \\
\hline
\end{tabular}


Table 2 PCR amplification procedure

\begin{tabular}{lllllll}
\hline $\begin{array}{l}\text { Target } \\
\text { gene }\end{array}$ & Predegeneration & Degeneration & Annealing & Extend & $\begin{array}{l}\text { Cycle } \\
\text { number }\end{array}$ & $\begin{array}{l}\text { posterior } \\
\text { extension }\end{array}$ \\
\hline PhyA2 & $94{ }^{\circ} \mathrm{C} 5 \mathrm{~min}$ & $94{ }^{\circ} \mathrm{C} 55 \mathrm{~s}$ & $\begin{array}{r}58{ }^{\circ} \mathrm{C} \\
55 \mathrm{~s}\end{array}$ & $\begin{array}{r}72{ }^{\circ} \mathrm{C} \\
80 \mathrm{~s}\end{array}$ & 32 & $72{ }^{\circ} \mathrm{C} 10 \mathrm{~min}$ \\
\hline
\end{tabular}

\section{Rooting}

After the adventitious buds grew to $2-3 \mathrm{~cm}$, they were transferred to the rooting medium. After 1 week, adventitious roots were detected, enabling the transfer of plants to soil.

Detection of PhyA2 in maize plants

\section{PCR analysis of transgenic plants}

Genomic DNA was extracted from herbicide-resistant $\mathrm{T}_{3}$ generation maize plants with a NuClean Plant Genomic DNA kit (Changchun Feikai Biological Co., Ltd., Economic Development Zone, Changchun City, Jilin Province). The maize genomic DNA was used as a template for a PCR with primers $S$ and AS. The plant expression vector carrying PhyA2 was used as the positive control, whereas the genomic DNA from untransformed maize plants served as the negative control. The PCR conditions are listed in Table 2. The PCR products were analyzed by agarose gel electrophoresis. The $\mathrm{T}_{3}$ generation maize plants that were confirmed by PCR to be transgenic were self-pollinated to produce seeds. The $\mathrm{T}_{3}$ generation seeds were germinated to obtain $\mathrm{T}_{4}$ generation transgenic maize plants, which were verified by PCR.

\section{Southern hybridization analysis of transgenic plants}

Large quantities of genomic DNA were extracted from the $\mathrm{T}_{4}$ generation transgenic maize plants and untransformed maize plants (positive control) according to a modified CTAB method (Abdel and Osman 2017). A Southern blot analysis was completed with purified $P h y A 2$ as the probe as well as the plant expression vector carrying $P h y A 2$ and the genomic DNA from untransformed maize plants as the positive and negative controls, respectively. Specifically, 10-15 $\mu \mathrm{g}$ maize genomic DNA was digested with HindIII for $16 \mathrm{~h}$. The digested DNA was separated in a $0.8 \%$ agarose gel and then transferred to a nitrocellulose membrane in a $20 \times \mathrm{SSC}$ solution. The membrane was then incubated at $80{ }^{\circ} \mathrm{C}$ for $2 \mathrm{~h}$, after which the DNA was hybridized with the probe.

\section{Reverse transcription PCR analysis of transgenic plants}

Total RNA was extracted from the roots of transgenic maize plants and reverse transcribed to cDNA. Total RNA was also extracted from the roots of untransformed maize plants and reverse transcribed (negative control). The cDNA samples for the transgenic and control maize plants were used as the templates for a PCR amplification of PhyA2 with primers $S$ and AS (Table 1). The maize $E F-1 \alpha$ gene, which was used as the internal reference control, was amplified by PCR with primers P1 and P2 to produce a 213-bp fragment (Table 3). The PCR conditions are listed in Table 2.

\section{Quantitative real-time PCR analysis of transgenic plants}

Total RNA was extracted from the roots, stems, and leaves of untransformed (control) and transgenic maize plants and reverse transcribed to produce cDNA for a quantitative real-time (qRT)-PCR analysis of PhyA2 expression. The maize beta-actin gene (GenBank accession number: nm_001252731.2) was selected as the internal reference control. Primers QFACT and QRACT (Table 4) were designed based on the PhyA2 sequence. The qRT-PCR analysis was completed with the SYBR Green fluorescent dye. The reaction conditions are listed in Table 5. Each sample was analyzed with three replicates. The relative PhyA2 expression levels in the different maize tissues were calculated according to the $2^{-\Delta \Delta C t}$ method (Yueai et al. 2014).

\section{Preparation of the phosphorus concentration standard curve}

A phosphorus concentration standard curve was prepared as previously described (Safety certificate 2009). Additionally, a published method for analyzing 

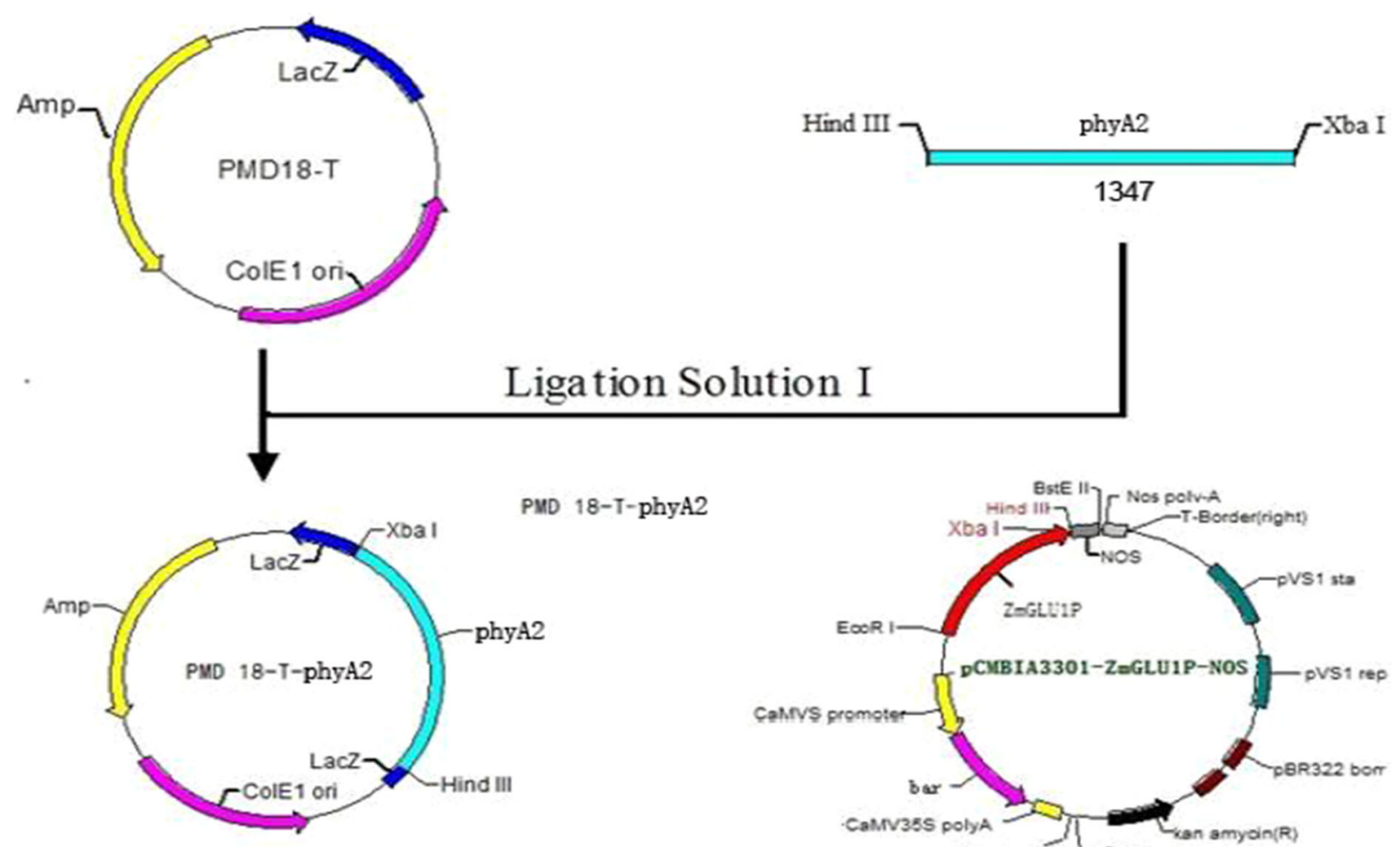

Ligation Solution I

MD 18-T-phyA2
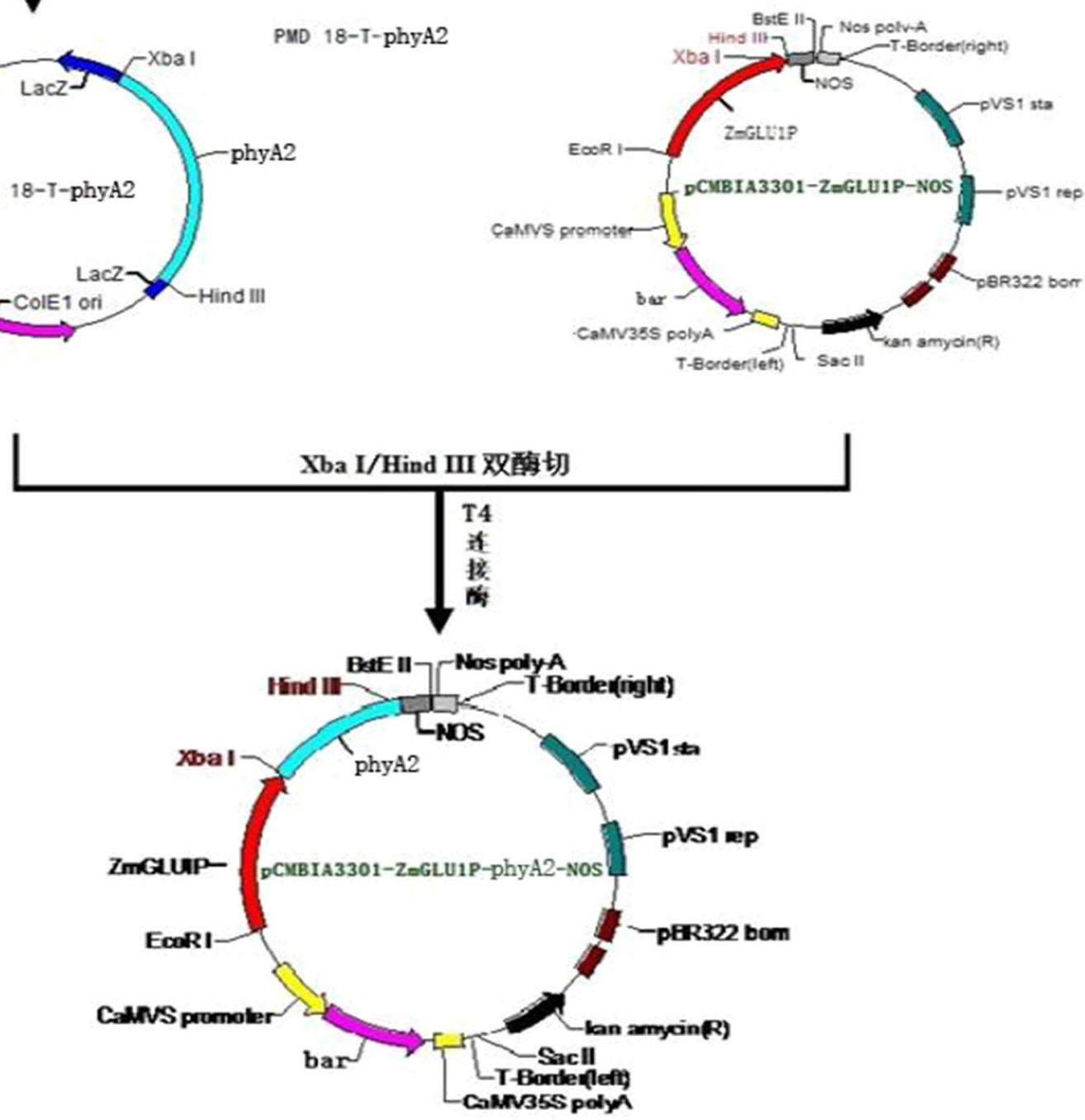

Fig. 1 The process of the construction of plant expression vector

plant root tissue phytase (Zhang 2009) was modified to examine the $\mathrm{T}_{4}$ generation transgenic maize plants. Specifically, $2 \mathrm{~g}$ root tissue was ground to a homogenate, which was then mixed with $8.0 \mathrm{~mL}$ extraction solution $(0.25 \mathrm{~mol} / \mathrm{L}$ sodium acetate, $0.05 \%$ Triton $\mathrm{X}-100$, and $0.05 \%$ bovine serum 
Table 3 Primer sequences

\begin{tabular}{ll}
\hline Name & Primer sequences \\
\hline EF-1 $\alpha-P 1$ & GCTTCACGTCCCAGGTCATC \\
EF-1 $\alpha-P 2$ & TAGGCTTGGTGGGTATCATC \\
\hline
\end{tabular}

Table 4 Primer sequences

\begin{tabular}{ll}
\hline Name & Primer sequences \\
\hline PhyA2-QFACT & ATCTTGACTGAGCGTGTTATTCC \\
PhyA2-QRACT & GCTGGTCCTGGCTGTCTCC \\
\hline
\end{tabular}

albumin). The resulting solution underwent an ultrasonication for $15 \mathrm{~min}$ at $37{ }^{\circ} \mathrm{C}$ in a water bath, after which it was centrifuged at $12,000 \mathrm{rcf}$.

\section{Determination of the phytase activity in transgenic plant root tissue}

Phytase activity was assessed in three parallel experiments as previously described (Bouchra et al. 2018; Bekalu et al. 2017). The root tissue phytase activity [i.e., 1 unit (U)] was defined as the amount of enzyme required to release $1 \mu \mathrm{mol}$ inorganic phosphorus from $0.10 \mathrm{mmol} / \mathrm{L}$ sodium phytate solution in $1 \mathrm{~min}$ at $37^{\circ} \mathrm{C}$ and pH 5.5. The enzyme activity was expressed as $\mathrm{U} / \mathrm{g}$.

\section{Analysis of the phosphorus in the rhizosphere of transgenic plants}

The $\mathrm{T}_{4}$ generation transgenic maize plants verified by the Southern blot analysis were grown in soil for an analysis of the organic phosphorus content in the rhizosphere (i.e., soil up to $20 \mathrm{~cm}$ deep and within $5 \mathrm{~cm}$ of the main root). Soil samples collected before the transgenic maize were planted were used as controls.

Table 5 PCR amplification procedure
Analysis of the agronomic characteristics

of transgenic maize plants

Three replicates of the $T_{3}$ and $T_{4}$ generation transgenic maize plants were grown in an experimental field at Jilin Agricultural University to evaluate the main agronomic traits. At maturity, plant height and other yield-related characteristics were analyzed.

\section{Results}

Construction and detection of a new plant expression vector

The results of an agarose gel electrophoresis (Fig. 2) revealed the PhyA2 fragment amplified by PCR was approximately $1400 \mathrm{bp}$ long, which was the expected size. The new plant expression vector was digested with $\mathrm{XbaI}$ and HindIII and the resulting fragments were examined in an agarose gel (Fig. 3). Two fragments were obtained following the enzymatic digestion, one of which was about $1400 \mathrm{bp}$, as expected for PhyA2. Thus, the PCR and restriction enzyme digestion confirmed that the new plant expression vector (pCAMBIA3301-ZmGLU1PPhyA2-Nos) was constructed correctly.

Agrobacterium tumefaciens-mediated genetic transformation of the maize callus

An A. tumefaciens-mediated method was used to transform a maize inbred line with PhyA2. Six herbicide-resistant $\mathrm{T}_{4}$ generation maize plants were obtained. The specific transformation process is presented in Fig. 4.

PCR detection of PhyA2 in transgenic maize plants

Genomic DNA was extracted from the leaves of transgenic maize plants for a PCR analysis to confirm the insertion of PhyA2. The PCR product was examined by $1 \%$ agarose gel electrophoresis. The

\begin{tabular}{llllll}
\hline Target gene & Predegeneration & Degeneration & Annealing & Extend & Cycle number \\
\hline Q-PhyA2 & $94{ }^{\circ} \mathrm{C} 30 \mathrm{~s}$ & $94{ }^{\circ} \mathrm{C} 10 \mathrm{~s}$ & $55^{\circ} \mathrm{C} 40 \mathrm{~s}$ & $72{ }^{\circ} \mathrm{C} 20 \mathrm{~s}$ & 40 \\
\hline
\end{tabular}




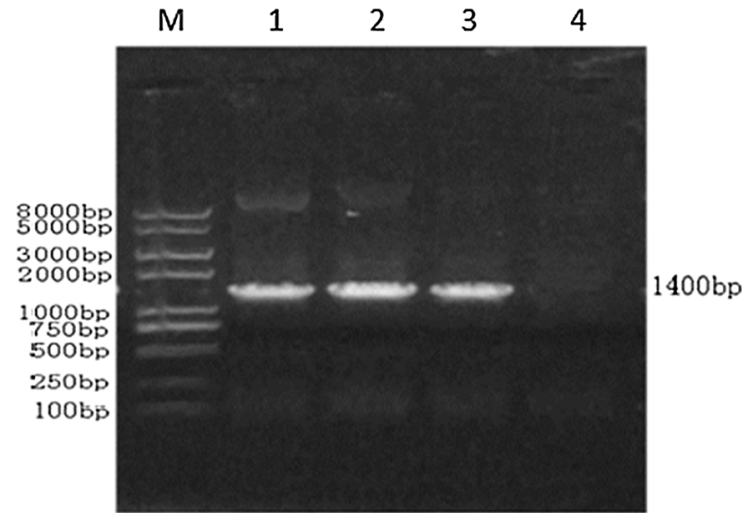

Fig. 2 The results of PCR identification. M: DL 8000 DNA Marker; 1-3: PCR products; 4: Contrast

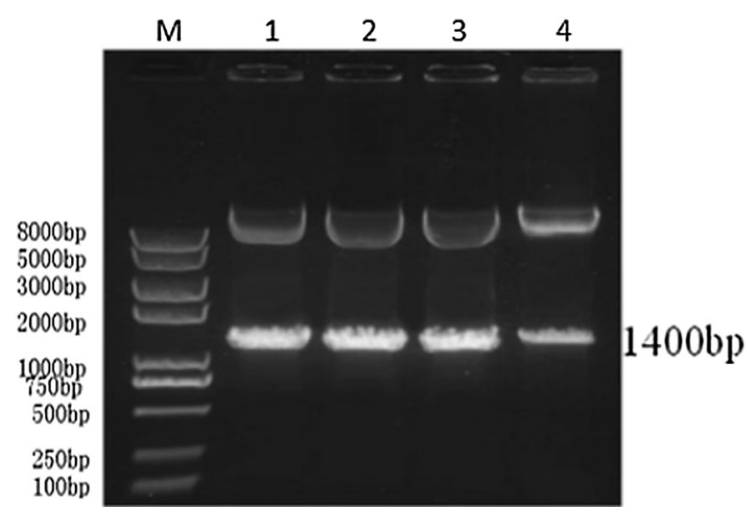

Fig. 3 Restriction enzyme digestion identification. M: DL8000 DNA Marker; 1-4: Digestion products

transgenic plants that produced the amplicon of the expected size were retained and self-pollinated to obtain $\mathrm{T}_{3}$ and $\mathrm{T}_{4}$ generation transgenic plants (Figs. 5 and 6).

Southern blot analysis of PhyA2 in transgenic maize plants

The $\mathrm{T}_{4}$ generation maize plants that tested positive for the presence of PhyA2 in the PCR assay were selected for a Southern blot. Their genomic DNA was extracted according to a modified CTAB method. The maize genome contains multiple HindIII restriction enzyme sites, whereas the PhyA2 fragment contains a single HindIII site at one end. Accordingly, HindIII was appropriate for the digestion of the maize genomic DNA to verify that PhyA2 had been integrated into the genome of transgenic plants. The Southern blot
(Fig. 7) revealed single-copy hybridization bands for two plants, whereas bands were undetectable for the untransformed control plants. Thus, the integration of $P h y A 2$ into the maize genome was confirmed.

Reverse transcription PCR identification of transgenic maize plants

The PhyA2 and $E F-1 \alpha$ gene sequences were amplified by PCR using cDNA prepared from the total RNA extracted from maize roots. The expected PhyA2 and $E F-1 \alpha$ sequences were amplified for the transgenic plants, whereas only the $E F-1 \alpha$ sequence was amplified for the untransformed plants (Fig. 8). Thus, the reverse transcription $\mathrm{PCR}$ results confirmed that PhyA2 was expressed in the roots of the transgenic maize plants.

Quantitative real-time PCR detection of transgenic lines

A qRT-PCR assay was performed to analyze the PhyA2 expression levels in the young leaves, roots, and stems of $\mathrm{T}_{4}$ generation transgenic plants verified by PCR and Southern blotting. The PhyA2 expression levels were calculated relative to the expression of the maize beta-actin gene. The qRT-PCR data indicated that PhyA2 was more highly expressed in the transgenic maize plants than in the control plants (Fig. 9). Specifically, the PhyA2 expression level was 3.75times higher in the transgenic maize roots than in the control roots. Additionally, the mean PhyA2 expression levels in the transgenic stems and leaves were respectively 1.42-times and 1.84-times higher than in the corresponding control tissues. Thus, PhyA2 was specifically expressed in the transgenic maize roots.

Determination of the phytase activity in the transgenic maize roots

\section{Phosphorus concentration standard curve}

A phosphorus concentration standard curve was prepared with the phosphorus concentration on the abscissa and the absorbance on the ordinate (Fig. 10). The linear regression equation was $\mathrm{y}=1.026 \mathrm{x}+$ $0.0053, \mathrm{R}^{2}=0.9996$, reflecting the relatively linear relationship between the phosphorus concentration and absorbance. 


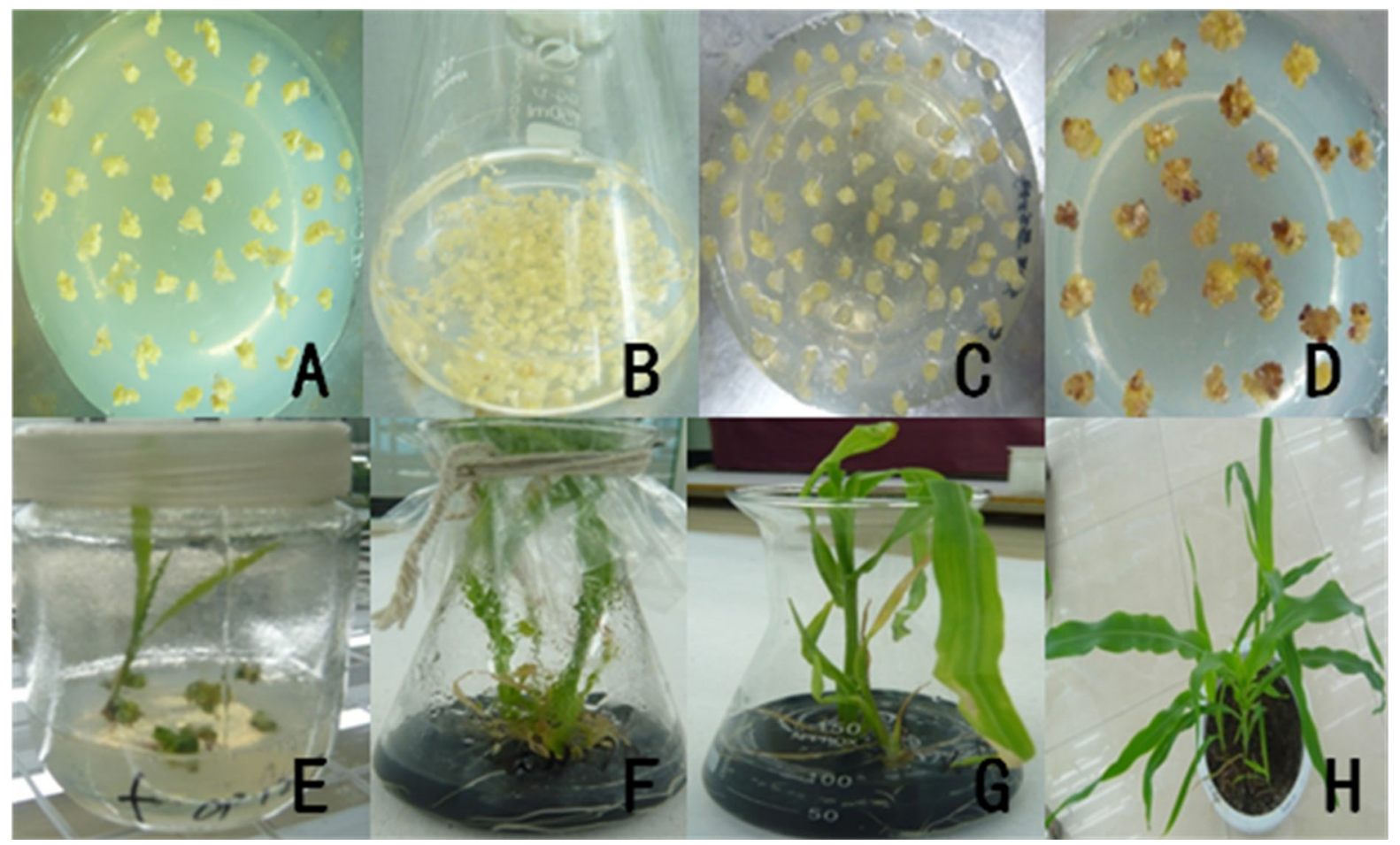

Fig. 4 Transforming into maize embryogenic callus via Agrobacterium tumefaciens-mediated method. (a) Preincubate of maize embryogenic callus. (b) Agrobacterium infection.

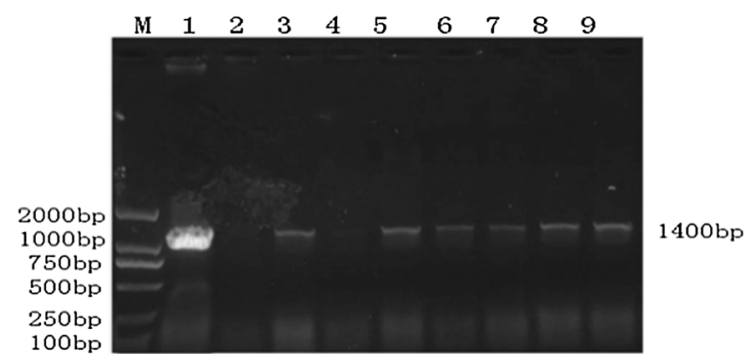

Fig. 5 PCR detection of $\mathrm{T}_{3}$ transgenic plants with PhyA2. M: DL2000 DNA Marker; 1: Positive control; 2: Non-transformed plant

\section{Phytase activity analysis of transgenic maize plants}

The phytase activity in the $\mathrm{T}_{4}$ transgenic maize roots was compared with that in the roots of untransformed plants. The phytase activity was significantly $(\mathrm{P}<0.05)$ higher in the transgenic roots than in the control roots (Table 6). On average, the phytase activity was 10.9-fold higher in the transgenic roots than in the control roots. The increased phytase (c) Co-cultivation. (d) Screening culture. (e) Differentiation culture. (f) Rooting culture. (g) Exercising plants. (h) Plants regeneration

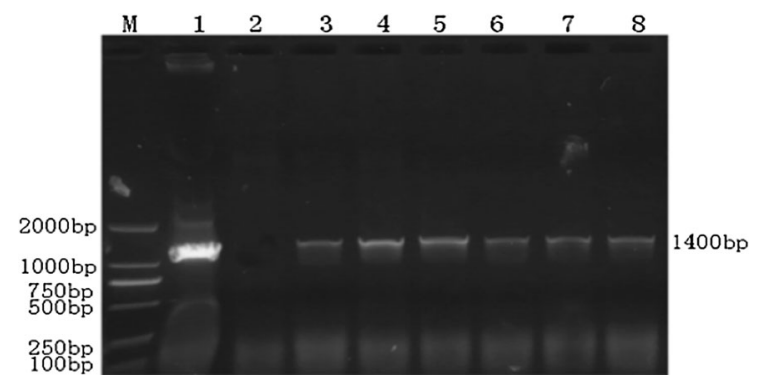

Fig. 6 PCR detection of $T_{4}$ transgenic plants with phyA2. M: DL2000 DNA Marker; 1: positive control; 2: non-transformed plant; 3-8: transgenic plants

activity of the transgenic roots ranged from 17.6-fold (T4-3-13) and 4.8-fold (T4-33-12) higher than that in the control roots. These results implied that PhyA2 was correctly incorporated into the genome and was being expressed in the roots of the transgenic maize plants. Moreover, the phytase produced in the transgenic plants appeared to be highly active. 


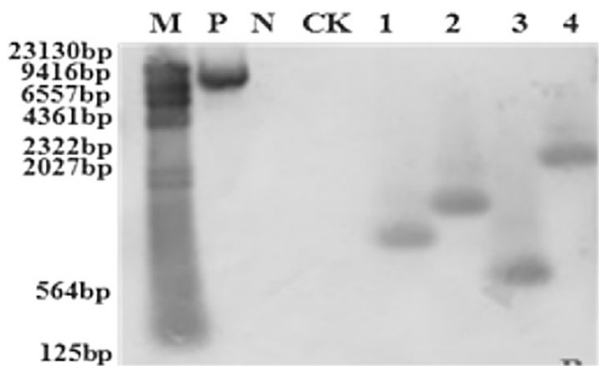

Fig. 7 Southern hybridization detection of T4 transgenic plant B: T4 generation of expression vector transgenic plants Southern hybridization detection; C: T4 generation infecting vector transgenic plants Southern hybridization detection; $\mathrm{M}: \lambda$ Hind III DNA Marker; P: Positive control; N: Water; CK: Negative control; $1-4$ : Positive plants

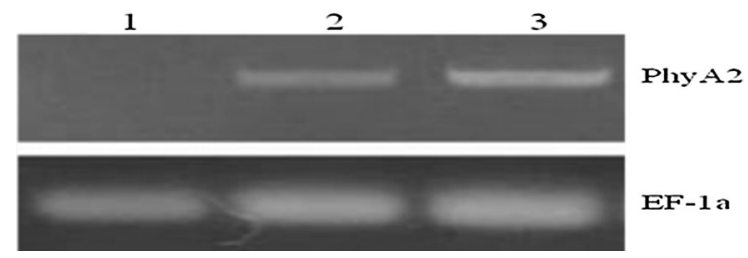

Fig. 8 RT-PCR analysis of $\mathrm{T}_{4}$ transgenic plants. 1: Nontransformed plant; 2-3: Transgenic plants

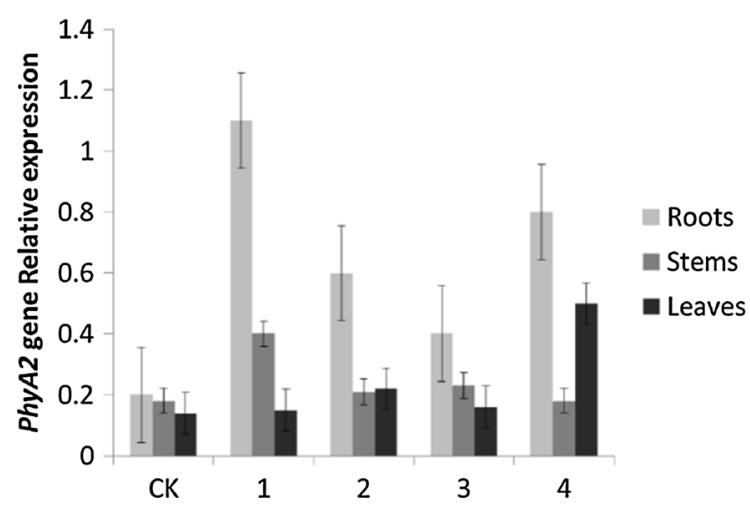

Fig. 9 Relative expression amount of PhyA2 gene. CK. Untransformed plants; $1-4$ : transformed plants

Analysis of the phosphorus content in the rhizosphere of the transgenic maize plants

A comparison of the rhizospheres of the transgenic and untransformed control maize plants revealed that the organic phosphorus content was 4.79-fold lower in the rhizosphere of the transgenic maize plants than in the control rhizosphere (Table 7). Thus, the expression of a phytase gene in maize roots appears to affect the soil organic phosphorus content.

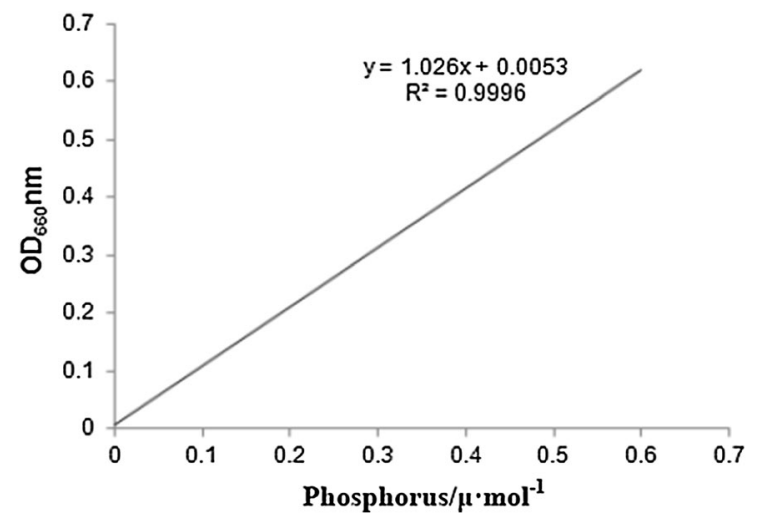

Fig. 10 Phosphorus standard curve

Agronomic characteristics of transgenic maize plants

\section{Phenological growth stages of transgenic maize}

There were no significant differences in the phenological growth stages of the transgenic (e.g., 35-15, 36-10, and 44-18) and control maize plants (Table 8). However, the tasseling stage occurred 3 days earlier in the transgenic plants than in the control plants. Additionally, the 6-13 transgenic plants reached maturity 4 days later than the controls.

\section{Analysis of the plant height and seed weight of the transgenic maize}

The ear length and thickness were similar in the transgenic and control plants (Table 9), but the effects of natural factors on the transgenic maize plants remain to be assessed. Additionally, although the height of individual transgenic maize plants differed from the mean height of control plants by $2-3 \mathrm{~cm}$, this difference was not significant. Accordingly, PhyA2 expression does not appear to affect maize plant height. Moreover, the mean 100-grain weights of the 6-13 and 13-7 transgenic plants were lower than that of the control plants. In contrast, the mean 100-grain weight of the other transgenic maize plants was $0.56 \mathrm{~g}$ higher than that of the control plants. Therefore, $P h y A 2$ expression may influence maize seed weights. 
Table 6 Phytase activity analysis of root system of transgenic plants

\begin{tabular}{llll}
\hline Plant number & Phytase activity $(\mathrm{U} / \mathrm{g})$ & Plant number & Phytase activity (U/g) \\
\hline $\mathrm{T}_{4}-3-13$ & $5.432 \mathrm{aA}$ & $\mathrm{T}_{4}-14-1$ & $2.983 \mathrm{gF}$ \\
$\mathrm{T}_{4}-4-20$ & $4.349 \mathrm{bB}$ & $\mathrm{T}_{4}-14-3$ & $2.374 \mathrm{hG}$ \\
$\mathrm{T}_{4}-5-4$ & $4.253 \mathrm{cC}$ & $\mathrm{T}_{4}-16-13$ & $2.417 \mathrm{hG}$ \\
$\mathrm{T}_{4}-6-13$ & $4.172 \mathrm{dD}$ & $\mathrm{T}_{4}-28-19$ & $2.214 \mathrm{iH}$ \\
$\mathrm{T}_{4}-13-7$ & $3.985 \mathrm{eE}$ & $\mathrm{T}_{4}-33-12$ & $1.510 \mathrm{jI}$ \\
$\mathrm{T}_{4}-13-11$ & $3.032 \mathrm{fF}$ & $\mathrm{CK}$ & $0.307 \mathrm{~kJ}$ \\
\hline
\end{tabular}

$T_{4}-3-13$ comes from $T_{3}-7-1$ of $T_{3}$ generation plants. $T_{4}-4-20$ comes from $T_{3}-5-2$ of $T_{3}$ generation plants. $T_{4}-5-4$ comes from $T_{3}-8-3$ plants of $T_{3}$ generation. $T_{4}-6-13$ comes from $T_{3}-9-4$ of $T_{3}$ generation plants. $T_{4}-13-7$ and $T_{4}-13-11$ came from the same $T_{3}$ plant $T_{3}-$ 16-7. $\mathrm{T}_{4}-14-1$ and $\mathrm{T}_{4}-14-3$ came from the same $\mathrm{T}_{3}$ plant $\mathrm{T}_{3}-20-3 . \mathrm{T}_{4}-16-13$ comes from $\mathrm{T}_{3}-22-6$ of $\mathrm{T}_{3}$ generation plants. $\mathrm{T}_{4}-28-19$ comes from $\mathrm{T}_{3}-23-4$ of $\mathrm{T} 3$ generation plants. $\mathrm{T}_{4}-33-12$ comes from $\mathrm{T}_{3}-27-9$ of $\mathrm{T}_{3}$ generation plants. The $5 \%$ level is significantly indicated by lowercase letters, and the $1 \%$ level is significantly indicated by uppercase letters

Table 7 Analysis of phosphorus content in rhizosphere soil of transgenic plants

\begin{tabular}{lllll}
\hline Plant number & $\begin{array}{l}\text { Total soil } \\
\text { phosphorus before } \\
\text { planting }\left(\mathrm{mg} \mathrm{kg}^{-1}\right)\end{array}$ & $\begin{array}{l}\text { Soil organic } \\
\text { phosphorus content } \\
\text { before planting }\left(\mathrm{mg} \mathrm{kg}^{-1}\right)\end{array}$ & $\begin{array}{l}\text { Total soil } \\
\text { phosphorus content } \\
\text { after planting }\left(\mathrm{mg} \mathrm{kg}^{-1}\right)\end{array}$ & $\begin{array}{l}\text { Soil organic } \\
\text { phosphorus content } \\
\text { after planting }\left(\mathrm{mg} \mathrm{kg}^{-1}\right)\end{array}$ \\
\hline $\mathrm{T}_{4}-4-8$ & 314.47 & 53.46 & 309.66 & $49.32^{* *}$ \\
$\mathrm{~T}_{4}-4-9$ & 263.94 & 44.87 & $255.71 *$ & $42.59^{*}$ \\
$\mathrm{~T}_{4}-5-14$ & 282.29 & 47.99 & $275.38^{*}$ & $43.87^{* *}$ \\
$\mathrm{~T}_{4}-6-8$ & 331.29 & 56.32 & $320.45^{* *}$ & $51.11^{* *}$ \\
$\mathrm{~T}_{4}-8-7$ & 402.59 & 68.44 & $392.55^{* *}$ & $64.63^{*}$ \\
$\mathrm{~T}_{4}-13-1$ & 213.94 & 36.37 & $204.86^{* *}$ & $33.46^{*}$ \\
$\mathrm{~T}_{4}-15-8$ & 275.35 & 46.81 & $264.49 * *$ & $45.71^{*}$ \\
$\mathrm{~T}_{4}-19-13$ & 292.00 & 49.64 & $281.33^{* *}$ & $45.36^{* *}$ \\
$\mathrm{~T}_{4}-22-3$ & 326.06 & 55.43 & $317.84 *$ & $52.18^{*}$ \\
$\mathrm{~T}_{4}-25-2$ & 361.70 & 61.49 & $352.73 *$ & $59.02^{*}$ \\
$\mathrm{CK}_{1}$ & 349.70 & 59.45 & 343.83 & 598.76 \\
$\mathrm{CK}_{2}$ & 376.54 & 62.73 & 371.62 & 62.86 \\
\hline
\end{tabular}

Note: Each set of data in the graph is the mean \pm standard deviation of three replicates of three sites in each plant. "*, **" represents the difference in significance between the transgenic positive plants and the untransformed plants, respectively. "*” stands for $0.01<\mathrm{P}<0.05$ for significant difference; “**” stands for $0.001<\mathrm{P}<0.01$ for significant difference

\section{Discussion}

Phytase was initially identified in 1915, and its considerable ability to degrade phytic acid was subsequently confirmed by Anderson (1941). The rapid development of biotechnology has enabled researchers to investigate the effects of the ectopic expression of phytase genes in transgenic plants. For example, Abul et al. (1999) isolated a PhyA gene from A. ficuum, and successfully expressed it as a recombinant gene in tobacco leaves. Although the molecular weight and optimal $\mathrm{pH}$ was lower for the expressed product than for the natural phytase, the biological characteristics were otherwise identical. The PhyA2 gene was successfully cloned from $A$. ficuum cDNA in this study.

In terms of molecular biology, a vector can be used to transfer a target gene into the receptor material and subsequently control the expression of the target gene (Chen 1994). A good plant expression vector is important for the successful transformation of plants with exogenous DNA material. Different types of regulatory elements in plant expression vectors can directly affect the expression of recombinant phytase 
Table 8 Observation values of phenological period and growth period

\begin{tabular}{|c|c|c|c|c|}
\hline Strain & $\begin{array}{l}\text { Seeding stage/days } \\
\text { from sowing }\end{array}$ & $\begin{array}{l}\text { Tasseling stage/days } \\
\text { from sowing }\end{array}$ & $\begin{array}{l}\text { Spinning stage/days } \\
\text { from sowing }\end{array}$ & $\begin{array}{l}\text { Mature stage/days } \\
\text { from sowing }\end{array}$ \\
\hline GSH9901-3-13 & 13 & 75 & 83 & 144 \\
\hline GSH9901-4-20 & 14 & 76 & 83 & 141 \\
\hline GSH9901-5-2 & 14 & 74 & 82 & 144 \\
\hline GSH9901-5-4 & 14 & 74 & 83 & 143 \\
\hline GSH9901-6-13 & 14 & 75 & 82 & 145 \\
\hline GSH9901-13-7 & 13 & 75 & 81 & 144 \\
\hline GSH9901-13-11 & 13 & 73 & 83 & 140 \\
\hline GSH9901-14-1 & 13 & 76 & 84 & 142 \\
\hline GSH9901-14-3 & 13 & 77 & 83 & 141 \\
\hline GSH9901-16-13 & 13 & 77 & 82 & 141 \\
\hline GSH9901-28-19 & 13 & 74 & 82 & 141 \\
\hline GSH9901-33-12 & 13 & 74 & 83 & 142 \\
\hline GSH9901-35-15 & 13 & 75 & 81 & 139 \\
\hline GSH9901-36-10 & 12 & 72 & 80 & 140 \\
\hline GSH9901-36-12 & 12 & 73 & 81 & 140 \\
\hline GSH9901-37-15 & 13 & 73 & 81 & 140 \\
\hline GSH9901-44-18 & 12 & 72 & 80 & 139 \\
\hline GSH9901-CK & 13 & 75 & 82 & 141 \\
\hline
\end{tabular}

genes in plants. For example, the $Z m G L U 1$ promoter may be used for the root-specific expression of a transgene. In the current study, PhyA2 was inserted into a plant expression vector containing the $Z m G L U 1$ promoter for the root-specific expression of the phytase gene. This study was similar to that conducted by Cui (2007).

Our gene expression analyses confirmed that the inserted PhyA2 gene was expressed in the $\mathrm{T}_{3}$ and $\mathrm{T}_{4}$ generation transgenic maize plants. Additionally, the $P h y A 2$ expression level in the transgenic maize plants was higher in the roots than in the leaves. The observed phytase activities in this study were consistent with those determined by Zhang et al. (2010). Specifically, the phytase produced in the transgenic maize roots was able to degrade sodium phytate; however, the relatively low phytase activity in this study may have been due to the instability of PhyA2, resulting in impure transgenic maize plants. $\mathrm{Li}$ et al. (2009) reported similar results for their investigation of transgenic soybean plants expressing a phytase gene.

William et al. (1990) were the first to produce fertile transgenic maize plants, making it possible to improve maize traits via methods commonly used for biotechnology research. Our analysis of soil phosphorus levels revealed a decrease in the organophosphorus content in the rhizosphere of transgenic plants relative to the content in the control rhizosphere. This decrease may reflect the degradation and uptake of organophosphorus by the transgenic plants expressing PhyA2; however, the phosphorus use efficiency was relatively low. Song et al. (2008) explored the effects of phytase on soil organophosphorus contents. Their results indicated that increases in the abundance of active or moderately active organophosphorus compounds in the soil may be related to increases in phosphatase activities. Moreover, the phosphatase activity may decrease with increases in moderately or highly stable organophosphorus compounds in the soil.

In this study, analyses of phenological growth stages revealed a lack of significant differences between the PhyA2-expressing transgenic maize plants and the control plants. Additionally, there were no significant differences in the physiological indices of the transgenic and control maize plants, possibly because the plants were not exposed to adverse environmental conditions. Furthermore, PhyA2 
Table 9 Field agronomic shape survey and overplanting

\begin{tabular}{|c|c|c|c|c|c|c|c|c|}
\hline Strain & $\begin{array}{l}\text { Average } \\
\text { lodging rate }(\%)\end{array}$ & $\begin{array}{l}\text { The average } \\
\text { bald tip }(\mathrm{cm})\end{array}$ & $\begin{array}{l}\text { Plant } \\
\text { height }(\mathrm{cm})\end{array}$ & $\begin{array}{l}\text { Ear } \\
\text { length }(\mathrm{cm})\end{array}$ & $\begin{array}{l}\text { Ear } \\
\text { diameter }(\mathrm{cm})\end{array}$ & $\begin{array}{l}\text { Kernels } \\
\text { per row }\end{array}$ & $\begin{array}{l}\text { Kernel } \\
\text { rows }\end{array}$ & $\begin{array}{l}\text { 100-grain } \\
\text { weight }(\mathrm{g})\end{array}$ \\
\hline GSH9901-3-13 & 8 & 0.6 & $154 \mathrm{aA}$ & 14.5 & 3.34 & 34 & 14 & $25.8 \mathrm{aA}$ \\
\hline GSH9901-4-20 & 5 & 0.8 & $154 \mathrm{aA}$ & 14.5 & 3.28 & 29 & 14 & $25.8 \mathrm{bA}$ \\
\hline GSH9901-5-2 & 3 & 0.25 & $153 \mathrm{aA}$ & 14.9 & 3.33 & 31 & 14 & $25.6 \mathrm{cB}$ \\
\hline GSH9901-5-4 & 5 & 0.65 & $153 \mathrm{aA}$ & 14.8 & 3.36 & 33 & 14 & $25.5 \mathrm{dC}$ \\
\hline GSH9901-6-13 & 5 & 0.8 & $153 \mathrm{aA}$ & 14.3 & 3.25 & 28 & 14 & $25.5 \mathrm{dD}$ \\
\hline GSH9901-13-7 & 5 & 0.5 & $153 \mathrm{aA}$ & 14.5 & 3.26 & 33 & 14 & $25.4 \mathrm{eE}$ \\
\hline GSH9901-13-11 & 2 & 1.3 & $152 \mathrm{aA}$ & 15.2 & 3.55 & 33 & 14 & $25.4 \mathrm{eE}$ \\
\hline GSH9901-14-1 & 6 & 0.83 & $152 \mathrm{aA}$ & 15.8 & 3.58 & 32 & 14 & $25.4 \mathrm{eF}$ \\
\hline GSH9901-14-3 & 5 & 1.1 & $152 \mathrm{aA}$ & 15.0 & 3.63 & 34 & 14 & $25.4 \mathrm{eG}$ \\
\hline GSH9901-16-13 & 3 & 0.85 & $152 \mathrm{aA}$ & 15.8 & 3.68 & 33 & 14 & $25.3 \mathrm{eH}$ \\
\hline GSH9901-28-19 & 5 & 0.6 & $152 \mathrm{aA}$ & 15.2 & 3.66 & 31 & 14 & $25.3 \mathrm{eI}$ \\
\hline GSH9901-33-12 & 5 & 1.2 & $152 \mathrm{aA}$ & 15.5 & 3.65 & 30 & 14 & $25.2 \mathrm{fJ}$ \\
\hline GSH9901-35-15 & 2 & 1.4 & $152 \mathrm{aA}$ & 14.8 & 3.59 & 32 & 14 & $25.0 \mathrm{gK}$ \\
\hline GSH9901-36-10 & 5 & 1.0 & $151 \mathrm{aA}$ & 14.5 & 3.53 & 32 & 14 & $24.9 \mathrm{hL}$ \\
\hline GSH9901-36-12 & 2 & 1.7 & $151 \mathrm{aA}$ & 14.6 & 3.63 & 29 & 14 & $24.9 \mathrm{iM}$ \\
\hline GSH9901-37-15 & 2 & 1.1 & $150 \mathrm{aA}$ & 14.2 & 3.65 & 28 & 14 & $24.7 \mathrm{kO}$ \\
\hline GSH9901-44-18 & 1 & 1.5 & $155 \mathrm{aA}$ & 14.9 & 3.85 & 32 & 14 & $24.6 \mathrm{iP}$ \\
\hline GSH9901-CK & 2 & 0.75 & $155 \mathrm{aA}$ & 15.8 & 3.63 & 33 & 14 & $24.8 \mathrm{jN}$ \\
\hline
\end{tabular}

The $5 \%$ level is significantly indicated by lowercase letters, and the $1 \%$ level is significantly indicated by uppercase letters

expression did not significantly influence plant height. However, there were some differences in the mean 100 -grain weight, with higher weights in the transgenic plants than in the controls, except for 6-13 and 13-7. These findings suggest that maize plants expressing a phytase gene may be able to take up organic phosphorus from the soil and transfer it to the developing ears.

In summary, compared with the control maize inbred line GSH9901, the introduction of PhyA2 into maize can positively affect the soil phosphorus use efficiency, plant growth state, and seed yield. Therefore, PhyA 2 may be useful for improving maize yield traits and phosphorus use efficiency.

Authors' contributions Peng Jiao and Wen-Ya Yuan designed and performed the experiments. Han-Dan Zhao, Jing Qu, Pi-Wu Wang analyzed the data, Peng Jiao and Wen-Ya Yuan wrote the paper, Shu-Yan Guan and Yi-Yong Ma full guided the experiments and the paper.

Funding This work was supported by the Jilin Provincial Natural Science Foundation Project [20190201168JC], Jilin Province Science and Technology Development Plan Project [20200402023NC], Jilin Province Key Technology R\&D
Project [20180201029NY] and Jilin Province Support for the Science and Technology Development Program [20190802012ZG]. Furthermore, the funding body have no role in designing of study, collection and interpretation of data or writing up the manuscript.

\section{Compliance with ethical standards}

Conflict of interest The authors declare that they have no competing interest.

Open Access This article is licensed under a Creative Commons Attribution 4.0 International License, which permits use, sharing, adaptation, distribution and reproduction in any medium or format, as long as you give appropriate credit to the original author(s) and the source, provide a link to the Creative Commons licence, and indicate if changes were made. The images or other third party material in this article are included in the article's Creative Commons licence, unless indicated otherwise in a credit line to the material. If material is not included in the article's Creative Commons licence and your intended use is not permitted by statutory regulation or exceeds the permitted use, you will need to obtain permission directly from the copyright holder. To view a copy of this licence, visit http://creativecommons.org/licenses/by/4.0/. 


\section{References}

Abdel LA, Osman G (2017) Comparison of three genomic DNA extraction methods to obtain high DNA quality from maize. Plant Methods 13:1

Abul HJ, Kandan S, Edward J et al (1999) Characterization of recombinant fungal phytase (phyA) expressed in tobacco leaves. Biochem Biophys Res Commun 264:201-206

Anderson RJ (1941) A contribution to the chemistry of phytin. J Biol Chem 17:171-190

Bekalu ZE, Madsen CK, Dionisio G, Brinch PH (2017) Aspergillus ficuum phytase activity is inhibited by cereal grain components. PLoS One 12(5)

Bouchra M, Ablaa K, Mohammed M, Laurie A, Odile D, Matthew B, Jean-Jacques D, Cherki G (2018) Phosphorus deficiency increases nodule phytase activity of faba beanrhizobia symbiosis. Acta Physiol Plant 40:63

Chen ZL (1994) Plant genetic engineering. Jilin Science and Technology Press, Changchun, pp 67-68

Cui XX (2007) Expression of root-specific promoter rRB7 in Arabidopsis thaliana and cotton. Chin Acad Agric Sci

Enqing H, Dazhi W, Yuanwen K, Jing C, Chengrong C, Xianjin H, Marijke H, Hui L, Yuguang Z (2018) Soil pH predominantly controls the forms of organic phosphorus in topsoils under natural broadleaved forests along a $2500 \mathrm{~km}$ latitudinal gradient. Geoderma 315:65-74

Li GL, Yang SH, Li MG et al (2009) Functional analysis of an Aspergillus ficuum phytase gene in Saccbaromyces cerevisiae and its root-specific, secretory expression in transgenic soybean plants. Biotechnol Lett 31(8):1297-1303

Safety certification. (2009). China's independent research and development of phytase gene maize was certified as safe. North Anim Husbandry 24:27

Sareh N, Mohammad JM, Ali BS, Mohammad GM (2018) The role of organic acids on the uptake and relationship of phosphorus and zinc in corn (Zea mays L.) by application of 32P and 65Zn radioisotopes. J Plant Nutr 41(7):846-855

Song D, Guan LZ, Wang JL, Gao Y, Yan L (2008) Effect of exogenous phytase on the content of soil organic phosphorus components. China Soil Fertil 2:24-26

Valeeva LR, Nyamsuren C, Sharipova MR, Shakirov EV (2018) Heterologous expression of secreted bacterial BPP and HAP phytases in plants stimulates Arabidopsis thaliana growth on phytate. Front Plant Sci 9:186

William J, Gordon-Kamm T, Michael S, Mary LM, Thomas RA, Richard JD, William GS, James VO, Sheryl AC, Whitney RA Jr, Nancy GW, Thomas BR, Catherine JM, Roger WK, Albert PK, Peggy GL (1990) Transformation of maize cells and regeneration of transgenic plants. Plant Cell 2:603

Wu RH, Li JQ, Zhuang KZ et al (2014) Effects of several trace elements on corn yield and economic benefits [J]. Mod Agric Sci Technol 19:15-15

Yan RY (2012) Creation and manufacture of phytase gene phyA transformed soybean and new transgenic materials. Hebei Agricultural University, Baoding

Yueai L, Chenlu Z, Hai L et al (2014) Validation of potential reference genes for qpcr in maize across abiotic stresses, hormone treatments, and tissue types. PLoS One 9(5):e95445

Zhang Q (2009) Study on the root expression function of phyA2 gene in transgenic maize. Chinese Academy of Agricultural Sciences, Beijing

Zhang Q, Chen JM, Yang W Z, et al (2010) Acquisition of constitutively expressed phyA2 gene in maize $[\mathrm{J}]$. Acta Agric Biotechnol 18(4):623-629 (in Chinese with English abstract)

Publisher's Note Springer Nature remains neutral with regard to jurisdictional claims in published maps and institutional affiliations. 